\title{
Duas décadas da Norma Brasileira de Comercialização de Alimentos para Lactentes: há motivos para comemorar?
}

\author{
Denise Cavallini Cyrillo, ${ }^{1}$ Flavia Mori Sarti, ${ }^{2}$ Elizabeth Mercier \\ Querido Farina ${ }^{3}$ e José Afonso Mazzon ${ }^{4}$
}

Como citar Cyrillo DC, Sarti FM, Farina EMQ, Mazzon JA. Duas décadas da Norma Brasileira de Comercialização de Alimentos para Lactentes: há motivos para comemorar? Rev Panam Salud Publica. 2009;25(2): $134-40$.

RESUMO Objetivo. Avaliar o impacto da Norma Brasileira de Comercialização de Alimentos para Lactentes no cenário do aleitamento materno e na regulação da comercialização de fórmulas infantis. Método. O artigo analisou dados de uma pesquisa de âmbito nacional realizada em 2000 na qual foram aplicados questionários estruturados em nove tipos de público-alvo. Foram realizadas 2848 entrevistas em uma amostra selecionada aleatoriamente em 159 municípios, distribuídos nos 26 estados brasileiros e Distrito Federal, escolhidos por análise de conglomerado. Resultados. A pesquisa mostrou uma percepção adequada dos agentes quanto à importância e duração ideal da amamentação. A duração mediana da amamentação no Brasil aumentou nas 2 últimas décadas, porém ainda se mostrou aquém do desejável. Os fatores responsáveis pelo desmame precoce incluíram trabalho e saúde precária da mãe, crenças sobre insuficiência do leite materno e orientações de profissionais de saúde. O conhecimento sobre a norma brasileira foi bastante restrito, mesmo entre profissionais de saúde.

Conclusões. A promoção do aleitamento materno no país deveria enfatizar a transcendência das barreiras culturais, educacionais e econômicas identificadas nos agentes envolvidos. A ação coordenada entre agentes públicos, agentes privados e terceiro setor para a disseminação da informação e do desejo de amamentar é desejável. A resistência à consolidação de parcerias deveria ser suprimida na busca de uma convergência institucional em prol do interesse maior expresso no contexto da norma brasileira: a proteção da saúde do lactente.

Palavras-chave Aleitamento materno, fórmulas infantis, legislação médica, política de saúde, propaganda, Brasil.

A amamentação é um tema de significativa relevância tendo em vista a im-

\footnotetext{
Universidade de São Paulo (USP), Faculdade de Economia. E-mail: dccyrill@usp.br

2 Universidade de São Paulo (USP), Escola de Artes, Ciências e Humanidades, Grupo Interdisciplinar de Física da Informação e Economia. Correspondência: Avenida Arlindo Béttio 1000, prédio I1, sala 3012-a, CEP 03828-000, São Paulo, SP, Brasil. Fone: +55-118381.2142; e-mail: flamori@usp.br

3 Universidade de São Paulo (USP), Faculdade de Economia. E-mail: emmqfari@usp.br

4 Universidade de São Paulo (USP), Faculdade de Administração. E-mail: jamazzon@usp.br
}

portância da nutrição nos primeiros anos de vida para o completo desenvolvimento do ser humano. O aleitamento materno contribui para a redução da mortalidade infantil e da incidência de enfermidades, sendo a medida mais eficiente e menos onerosa de combate a doenças infecciosas e desnutrição durante os primeiros meses de vida (1). A comparação dos resultados obtidos pela amamentação em relação à alimentação com substitutos do leite materno mostra uma redução estatisticamente significativa das taxas de morbidade e mortalidade infantil associadas ao aleitamento materno, mesmo em condições adequadas de moradia e higiene (2).

Assim, o leite materno constitui indubitavelmente o alimento ideal para a alimentação exclusiva durante os 6 primeiros meses de vida, devido à sua composição nutricional balanceada (3), à biodisponibilidade de nutrientes e à presença de fatores de crescimento $(4,5)$, en- 
zimas, hormônios e componentes imunológicos específicos ao crescimento e desenvolvimento infantis no primeiro ano de vida (6). Entretanto, as causas do desmame precoce são múltiplas: falta de informação, falta de incentivo ao aleitamento materno (7), pouca escolaridade materna, trabalho informal materno e introdução precoce de outros alimentos ou substitutos do leite materno, entre outros $(8,9)$.

No Brasil, a comercialização de alimentos substitutos do leite materno era regulada desde 1988 pela Norma Brasileira de Comercialização de Alimentos para Lactentes (10). Essa norma foi inspirada no Código Internacional de Comercialização de Substitutos do Leite Materno (11), estabelecido em 1981 pela Organização Mundial da Saúde (OMS), tendo o texto legal passado por duas revisões ao longo de quase 2 décadas de existência (12). Essas revisões resultaram das inúmeras críticas por parte dos diversos agentes ligados à temática da alimentação e saúde infantil, especialmente quanto à ambiguidade de vários trechos da norma brasileira, que permitiam interpretações diversas (13).

O principal objetivo da regulação da comercialização de alimentos para lactentes consiste na proteção da saúde infantil através da promoção do aleitamento materno, tendo em vista os benefícios associados à prática da amamentação (14). A ação governamental é necessária para harmonizar a busca do lucro pelas empresas produtoras de substitutos do leite materno com o interesse público de promoção da saúde da população. Na área da amamentação, essa harmonização se dá através da regulamentação das estratégias de comercialização dos produtos substitutos do leite materno e da promoção do aleitamento materno como melhor opção à alimentação infantil, tanto sob a ótica nutricional (dados os benefícios observados à saúde do lactente) quanto sob a ótica econômica (uma vez que poupa a renda familiar da despesa adicional com a alimentação do bebê) (15).

Antes da promulgação da nova versão da norma, no ano de 2002, quando passou a se denominar Norma Brasileira de Comercialização de Alimentos para Lactentes e Crianças de Primeira Infância, Bicos, Chupetas e Mamadeiras (16), o monitoramento das regras era usualmente efetuado por organizações não-governamentais de proteção ao aleitamento materno, que buscavam apontar transgressões na comercialização de alimentos substitutos do leite materno segundo interpretações próprias da legislação vigente. Em contrapartida, a indústria buscava explorar as brechas existentes no texto da norma para apoiar e justificar decisões estratégicas de comercialização dos produtos sob regulamentação segundo suas próprias interpretações $(12,13)$.

Esses confrontos eram extremamente desgastantes, com poucos resultados práticos para a totalidade dos agentes envolvidos $(17,18)$. Se, por um lado, a indústria alegava que constituía legítimo direito a busca de divulgação de seus produtos via propaganda, por outro lado diversas organizações não-governamentais indicavam a ocorrência de abusos em propagandas que exploravam a falta de conhecimento da população quanto à alimentação mais adequada para o lactente. Situados em meio às acusações mútuas entre a indústria e as organizações nãogovernamentais, o governo e os profissionais de saúde dividiam-se entre defesa e negligência com relação a determinadas regras expressas na norma (14). Todos esses processos fluíam em detrimento dos principais agentes contemplados no cerne da norma brasileira: mães e bebês (15). A última versão da norma brasileira, por sua vez, parece ter solucionado boa parte dos pontos de conflito (12).

Embora o Brasil tenha sido um dos países pioneiros na adaptação de uma versão nacional do Código Internacional de Comercialização de Substitutos do Leite Materno da OMS (11), verifica-se uma escassez de estudos sobre os determinantes da adesão ao aleitamento materno e do desmame precoce no Brasil. Sendo assim, o objetivo do presente artigo foi avaliar, a partir de dados de uma pesquisa realizada em 2000, o impacto da Norma Brasileira de Comercialização de Alimentos para Lactentes no cenário do aleitamento materno e na regulação da comercialização de alimentos substitutos do leite materno ao longo das 2 últimas décadas.

\section{MATERIAIS E MÉTODOS}

$\mathrm{O}$ artigo analisou dados secundários de uma pesquisa ${ }^{5}$ de âmbito nacional sobre a situação da amamentação no Brasil e o nível de conhecimento da norma

\footnotetext{
5 Fundação Instituto de Administração. Sistema de monitoramento da rotulagem e da comercialização de alimentos para lactentes [documento mimeografado]. São Paulo: Universidade de São Paulo; 2000.
}

brasileira nos diferentes tipos de públicoalvo (mães, mães potenciais, grávidas, parentes, médicos, nutricionistas, enfermeiros, supermercados e farmácias). A denominação mães potenciais foi empregada na pesquisa para se referir a mulheres em idade fértil que apresentavam potencial de tornarem-se mães em um curto período de tempo.

A pesquisa foi realizada no ano 2000 pela Fundação Instituto de Administração da Universidade de São Paulo mediante a aplicação de questionários estruturados elaborados especificamente para cada um dos nove grupos de públicoalvo, os quais foram entrevistados in loco, individualmente, por pesquisadores treinados. A amostra foi selecionada aleatoriamente em 159 municípios distribuídos nos 26 estados brasileiros e Distrito Federal, escolhidos randomicamente por análise de conglomerado com base em uma matriz de dados do Índice de Desenvolvimento Humano (IDH) do Fundo das Nações Unidas para a Infância (UNICEF). $\mathrm{O}$ banco de dados utilizado na pesquisa foi recentemente liberado para a elaboração e publicação de artigos em periódicos acadêmicos; assim, considerou-se oportuna a divulgação dos dados sobre este tema de amplo interesse no campo da saúde pública.

A pesquisa realizada envolveu 2848 entrevistas, sendo 1569 com mulheres (1 057 mães, 303 grávidas e 209 mães potenciais), 1000 com profissionais e instituições de saúde (353 pediatras, 133 nutricionistas, 128 enfermeiras e 386 instituições de saúde) e 279 com equipamentos varejistas (140 supermercados e 139 farmácias). Os indivíduos entrevistados em instituições de saúde e equipamentos varejistas foram selecionados de acordo com o perfil ocupacional relacionado ao público-alvo da norma, ou seja, profissionais de saúde diretamente em contato com lactantes e lactentes, assim como profissionais de vendas e promoção responsáveis por fórmulas infantis. Considerando-se que a amostra foi aleatoriamente selecionada, a margem de erro da pesquisa, com nível de $95 \%$ de probabilidade, foi de $2,5 \%$ para as mulheres, $3 \%$ para profissionais e instituições de saúde e $6 \%$ para equipamentos varejistas. O uso de bases de dados secundárias, limitadas à apresentação de estatísticas descritivas sobre a pesquisa realizada, impossibilitou a realização de análises estatísticas adicionais. 
Outras fontes de dados secundárias foram utilizadas para compor informações adicionais sobre a evolução do aleitamento materno e a demanda por fórmulas infantis substitutas do leite materno, de forma a expor o cenário e as tendências de atuação da Norma Brasileira de Comercialização de Alimentos para Lactentes. Efetuou-se o levantamento de dados referentes à evolução do aleitamento materno no país durante as 2 últimas décadas (19) e ao volume de vendas anuais de fórmulas infantis no Brasil (20). O volume de vendas de alimentos substitutos do leite materno foi convertido em demanda per capita (em quilos) em relação ao número de nascidos vivos por ano, segundo Estatísticas do Registro Civil do Instituto Brasileiro de Geografia e Estatística (IBGE) (21). A evolução de tais variáveis permitiu verificar possíveis modificações decorrentes da instituição do novo marco regulatório representado pela norma brasileira.

\section{RESULTADOS}

A partir dos dados da pesquisa nacional sobre aleitamento materno conduzida no ano 2000, constatou-se que o conhecimento dos agentes entrevistados quanto aos benefícios advindos do aleitamento materno era relativamente abrangente e apresentava noções bastante corretas. Entretanto, o nível de conhecimento das vantagens associadas à amamentação não atingiu $100 \%$ do público-alvo em nenhum dos quesitos apresentados (figura 1).

Paralelamente, a pesquisa mostrou que o conhecimento das mães acerca dos benefícios originários do aleitamento materno em comparação ao uso de substitutos do leite materno era bastante restrito. Somente 30\% das mães declararam não perceber nenhuma vantagem no uso de mamadeira com leite infantil industrializado em comparação com a amamentação, ou seja, $70 \%$ percebiam pelo menos uma vantagem no uso do leite infantil substituto do leite materno. As principais vantagens mencionadas pelas mães foram: sacia a fome do bebê (19\%), é a melhor alternativa caso a mãe não possa amamentar (13\%), alternativa à produção de pouco leite materno $(11 \%)$, permite maior liberdade da mãe $(11 \%)$, o leite industrializado é completo em vitaminas e minerais $(8 \%)$, praticidade $(7 \%)$ e opção para quem trabalha $(7 \%)$.

Os diferentes grupos entrevistados durante a pesquisa nacional sobre aleita-

FIGURA 1. Percepção dos agentes sobre vantagens do leite materno, Brasil, 2000

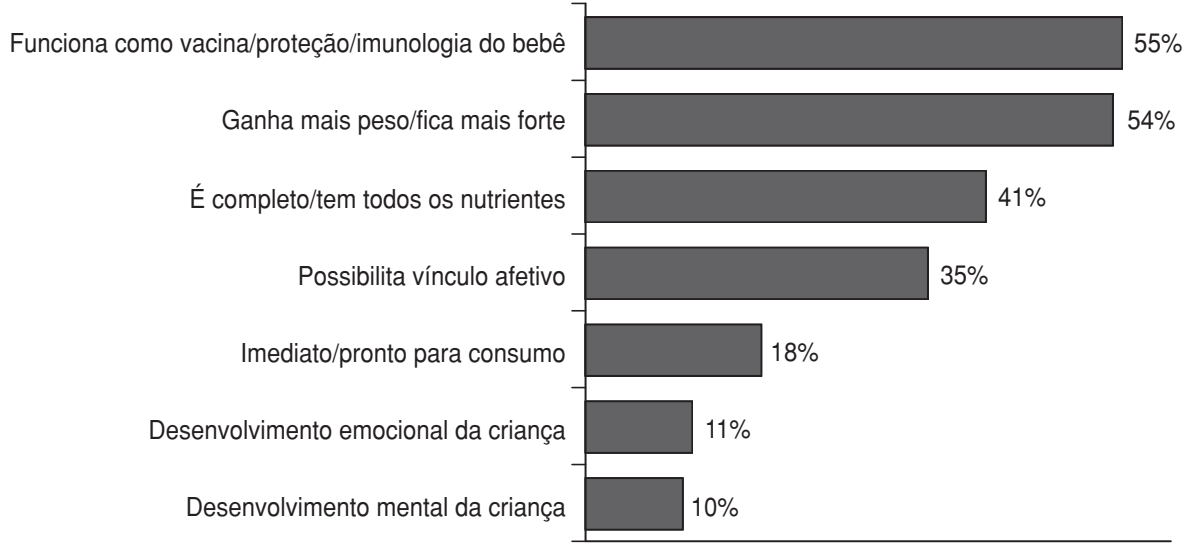

Fonte: Fundação Instituto de Administração. Sistema de monitoramento da rotulagem e da comercialização de alimentos para lactentes [documento mimeografado]. São Paulo: Universidade de São Paulo; 2000.

mento materno realizada no ano 2000 apontaram que a duração ideal da amamentação deve ser de, no mínimo, 6 meses. Entretanto, o cenário delineado a partir da pesquisa feita com mães foi bastante diferente: $69 \%$ declararam ter mantido aleitamento materno exclusivo durante período inferior a 4 meses, e somente $16 \%$ declararam adesão ao aleitamento exclusivo por pelo menos 6 meses. Entre as mães que interromperam o aleitamento materno e o substituíram totalmente por alimentos complementares, $28 \%$ o fizeram antes de o bebê completar 4 meses de idade, e $58 \%$, antes dos 6 meses. Além disso, 28\% das mães declararam ter utilizado mamadeira na alimentação do bebê durante o período de internação pós-parto.

O processo de introdução de alimentos na dieta do lactente foi ainda menos apropriado, sendo bastante comum a introdução de alimentos complementares caseiros ou industrializados desde os primeiros meses de vida. Os dados da pesquisa nacional demonstraram que a maioria das mães oferecia principalmente alimentos caseiros (suco de frutas, papinha ou sopinha, água com ou sem açúcar e chá) por desconhecer que não há necessidade de complementação do leite materno antes dos 6 meses de idade. Os alimentos introduzidos mais precocemente na alimentação do lactente foram chás, água pura ou com açúcar e substitutos do leite materno (tabela 1).

As principais justificativas apresentadas pelas mães para a introdução de alimentos ou líquidos na alimentação do bebê foram: recomendação do médico ou profissional de saúde (45\%), achavam que este seria o período apropriado para a introdução de novos alimentos $(40 \%)$, achavam que o bebê estava com fome $(26 \%)$, bebê estava chorando (19\%) e recomendação da mãe ou de parentes próximos (18\%).

Entre os fatores de influência para o início do processo de desmame do bebê, destacaram-se: motivações relacionadas ao trabalho e à disponibilidade de tempo da mãe, crenças sobre qual deve ser a duração da amamentação e sobre o valor nutricional insuficiente do leite materno, orientação de profissionais de saúde e informações errôneas veiculadas em meios de comunicação diversos (revistas, folhetos, cursos, etc.). Outro conjunto de fatores mencionado para explicar o desmame consistiu em motivações decorrentes de dificuldades da mãe, tais como impossibilidade de amamentar pela identificação de doenças (HIV, por exemplo), uso de medicamentos e fraqueza decorrente de má alimentação (tabela 2).

A maioria das mães entrevistadas na pesquisa nacional de 2000 declarou trabalhar fora de casa (56\%), sendo que $75 \%$ trabalhavam fora por períodos superiores a 6 horas diárias. Embora a maioria das mães tenha usufruído de licença-maternidade, $80 \%$ declararam que os locais de trabalho não apresentavam creches ou instalações para as mães amamentarem os bebês, sendo o retorno ao trabalho apontado como motivo para o desmame.

A mesma pesquisa mostrou que o papel do médico como fonte de informações sobre amamentação tem signi- 
TABELA 1. Alimentos oferecidos ao bebê no primeiro ano de vida e tempo médio de introdução do alimento, Brasil, 2000

\begin{tabular}{|c|c|c|c|}
\hline \multirow[b]{2}{*}{ Alimento } & \multirow[b]{2}{*}{$\begin{array}{c}\text { Mães que } \\
\text { ofereceram o } \\
\text { alimento (\%) }\end{array}$} & \multicolumn{2}{|c|}{$\begin{array}{l}\text { Tempo médio de introdução } \\
\text { do alimento (meses) }\end{array}$} \\
\hline & & $\begin{array}{l}\text { Como primeiro } \\
\text { alimento }\end{array}$ & $\begin{array}{l}\text { Como segundo } \\
\text { ou terceiro } \\
\text { alimento }\end{array}$ \\
\hline Suco natural de frutas caseiro & 76 & 4,5 & 4,5 \\
\hline Papinha/sopinha natural de verduras/ & & & \\
\hline legumes caseira & 75 & 5,3 & 5,3 \\
\hline Água pura ou com açúcar & 72 & 2,9 & 3,1 \\
\hline Chá & 65 & 2,2 & 2,4 \\
\hline $\begin{array}{l}\text { Leite infantil industrializado substituto } \\
\text { do leite materno }\end{array}$ & 47 & 2,2 & 2,9 \\
\hline Papinha/sopinha/mingau industrializado & & & \\
\hline pronto para uso & 37 & 5,0 & 6,0 \\
\hline logurte e similares & 29 & 5,3 & 6,7 \\
\hline Carne, ovo, peixe ou frango & 28 & 6,5 & 7,2 \\
\hline Leite em pó & 22 & 3,5 & 4,9 \\
\hline Suco natural de verduras/legumes caseiro & 18 & 5,5 & 5,6 \\
\hline Leite puro industrializado em saquinho/ & 13 & 37 & 45 \\
\hline
\end{tabular}

Fonte: Fundação Instituto de Administração. Sistema de monitoramento da rotulagem e da comercialização de alimentos para lactentes [documento mimeografado]. São Paulo: Universidade de São Paulo; 2000.

TABELA 2. Fatores de influência para o início do desmame, Brasil, 2000

\begin{tabular}{lc}
\hline \multicolumn{1}{c}{ Motivos para o desmame } & $\%$ \\
\hline Objetivos & \\
Tempo disponível da mãe & 41 \\
Trabalho profissional & 28 \\
Culturais & 40 \\
O tempo de amamentação no peito foi suficiente & 30 \\
Leituras e informações de revistas, folhetos, cursos, etc. & \\
Terceiros & 38 \\
Orientação do médico & 18 \\
Orientação de familiares e amigos & 7 \\
Orientação de farmacêutico e enfermeiro & \\
Dificuldades da mãe & 40 \\
Leite secou/insuficiente & 29 \\
Leite não descia/não teve leite & 22 \\
Mãe doente/debilitada/fraca & 21 \\
Leite em volume insuficiente e fraco & 21 \\
Uso de remédios & 19 \\
Problema nos seios & 17 \\
Fraqueza devido à má alimentação & 8 \\
Gravidez & \\
Dificuldades do bebê & 26 \\
Usou mamadeira e recusou seio & 25 \\
Recusou peito & 19 \\
Chorava muito & 18 \\
Não sugava & 17 \\
Ficou fraco/não ganhava peso & \\
\hline
\end{tabular}

Fonte: Fundação Instituto de Administração. Sistema de monitoramento da rotulagem e da comercialização de alimentos para lactentes [documento mimeografado]. São Paulo: Universidade de São Paulo; 2000.

ficativo destaque para grande parte das mães: $55 \%$ consideraram importante a orientação do médico na decisão de parar de amamentar e $40 \%$ citaram o pediatra como fonte do conhecimento sobre leites infantis industrializados ou outros alimentos complementares para o bebê. Paralelamente, os médicos declararam que a recomendação do uso de leites infantis industrializados em substituição ao leite materno antes do sexto mês de idade do bebê é efetuada em decorrência de solicitações e queixas das próprias mães pela necessidade de trabalhar $(87 \%)$, crença de que o leite materno é insuficiente e de que por isso o bebê chora $(65 \%)$ e recusa em amamentar por receio de problemas estéticos $(48 \%)$.

Finalmente, a pesquisa mostrou que o conhecimento da norma brasileira é praticamente nulo entre mães, grávidas, mães potenciais, supermercados e farmácias, e que é baixo entre profissionais de saúde (pediatras, nutricionistas e enfermeiras) e em instituições (tabela 3).

A consulta às outras fontes de dados secundárias $(19,20)$ revelou que o cenário da amamentação após quase 2 décadas de regulação pela Norma Brasileira de Comercialização de Alimentos para Lactentes evoluiu positivamente (19), sendo registrados avanços na duração mediana e na frequência da amamentação aos 4 e 5 meses de idade do bebê (tabela 4). Além disso, a análise de dados de vendas de alimentos substitutos do leite materno ao longo das 2 últimas décadas no país (20) permitiu verificar uma tendência declinante da demanda anual per capita de fórmulas infantis substitutas do leite materno no Brasil desde 1986, período anterior ao início do debate acerca do estabelecimento de legislação nacional restritiva à comercialização de produtos para lactentes. Adicionalmente, nota-se o registro de três pontos de significativa queda no volume de vendas anuais per capita de fórmulas infantis, principal categoria de produtos regulamentada pela Norma Brasileira de Comercialização de Alimentos para Lactentes; tais pontos coincidem com os anos de aprovação da primeira versão (1988), da primeira revisão (1992) e da segunda revisão da norma (2002) (figura 2) (20).

\section{DISCUSSÃO}

O presente artigo buscou contribuir para o esclarecimento de alguns mecanismos subjacentes às causas do desmame precoce no Brasil, concentrando-se especialmente em questões relativas à Norma Brasileira de Comercialização de Alimentos para Lactentes. Embora a decisão de amamentar e a adoção de práticas que prolonguem a duração do aleitamento dependam fundamentalmente da mãe, uma ampla rede de agentes transmite informações e influencia a decisão materna de adesão à amamentação, gerando efeitos sobre o comportamento individual ao criar ou reforçar ideais de senso comum e disseminar crenças baseadas na difusão de informações dúbias (22). 
TABELA 3. Conhecimento da Norma Brasileira de Comercialização de Alimentos para Lactentes, Brasil, 2000

\begin{tabular}{lccc}
\hline \multicolumn{1}{c}{ Público-alvo } & $\begin{array}{c}\text { Não conhece } \\
(\%)\end{array}$ & $\begin{array}{c}\text { Conhece e não leu } \\
(\%)\end{array}$ & $\begin{array}{c}\text { Conhece e leu } \\
(\%)\end{array}$ \\
\hline Mães & 93,5 & 6,0 & 0,6 \\
Grávidas & 96,0 & 4,0 & $\ldots$ a $^{\mathrm{a}}$ \\
Mães potenciais & 91,8 & 7,2 & 1 \\
Pediatras & 46,1 & 36,3 & 34,6 \\
Nutricionistas & 29,3 & 36,1 & 14,8 \\
Enfermeiras & 64,1 & 21,1 & 21,8 \\
Instituições de saúde & 53,9 & 24,4 & 2,9 \\
Supermercados & 79,2 & 17,9 & 0,7 \\
Farmácias & 89,9 & 9,4 & \\
\hline
\end{tabular}

Fonte: Fundação Instituto de Administração. Sistema de monitoramento da rotulagem e da comercialização de alimentos para lactentes [documento mimeografado]. São Paulo: Universidade de São Paulo; 2000.

a Nenhuma declaração.

TABELA 4. Evolução do aleitamento materno no Brasil, 1989-1999

\begin{tabular}{lccc}
\hline \multicolumn{1}{c}{ Variável } & $1989^{\mathrm{a}}$ & $1996^{\mathrm{b}}$ & $1999^{\mathrm{c}}$ \\
\hline Duração mediana (meses) & 5,5 & 7,0 & 9,9 \\
Frequência de amamentação aos 4 meses de idade & $61,6 \%$ & $71,7 \%$ & $77,0 \%$ \\
Frequência de amamentação aos 6 meses de idade & $49,9 \%$ & $59,8 \%$ & $69,0 \%$ \\
Frequência de amamentação aos 12 meses de idade & $29,3 \%$ & $37,4 \%$ & $35,0 \%$ \\
\hline
\end{tabular}

Fonte: Araújo (19).

a Pesquisa Nacional de Saúde e Nutrição (PNSN).

b Pesquisa Nacional sobre Demografia e Saúde (PNDS).

c Pesquisa de prevalência de aleitamento materno nas capitais brasileiras e Distrito Federal realizada pelo Ministério da Saúde.

FIGURA 2. Evolução da demanda efetiva de fórmulas infantis substitutas do leite materno, Brasil, 2003

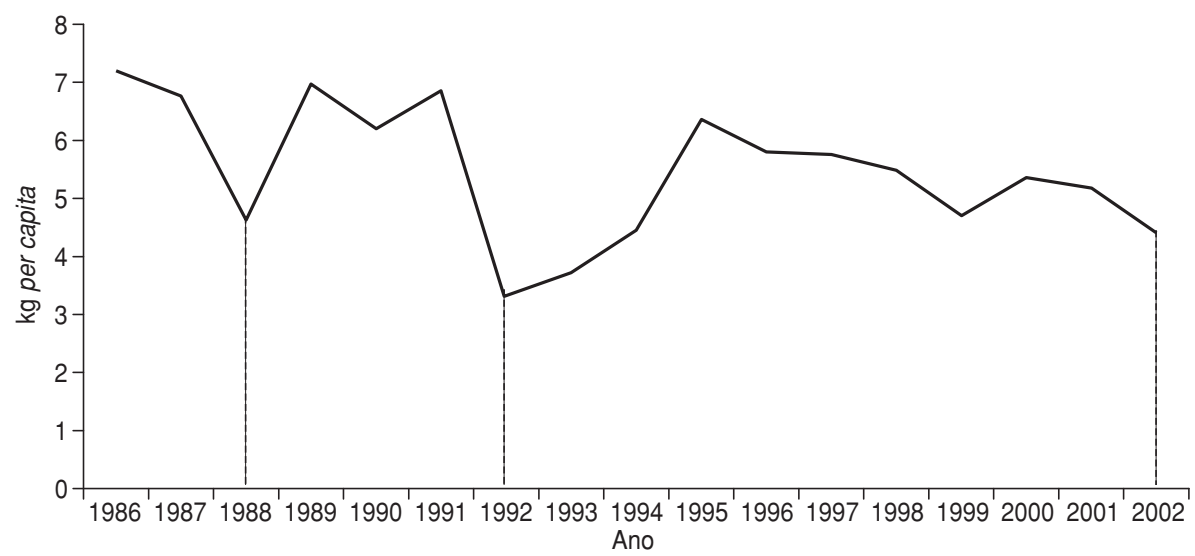

Fonte: Machado (20).

A análise da evolução da demanda per capita anual de fórmulas infantis (20), associada à observação do panorama histórico do aleitamento materno no Brasil (19), permitiu identificar algumas possíveis associações entre as variáveis em análise. A tendência verificada na demanda anual efetiva por fórmulas infantis foi declinante, especialmente nos anos da instituição e da publicação das duas revisões da Norma Brasileira de Comercialização de Alimentos para Lactentes (1988, 1992 e 2002), em conjunção com a introdução no país da Iniciativa Hospital Amigo da Criança (1992), proposta formulada pela OMS em associação com o UNICEF (23) que visa a promover ações de incentivo ao aleitamento ma- terno (por exemplo, aconselhamento a profissionais de saúde) e a coibir práticas que possam reduzir a frequência da amamentação e interferir negativamente na estimulação mamária e na produção do leite materno (por exemplo, a adoção precoce de fórmulas infantis, suplementos ou outros alimentos em ambiente hospitalar $)(7,24,25)$. Além disso, a proibição de ações de promoção da comercialização de fórmulas infantis, inclusive via supressão de campanhas de marketing nos meios de comunicação de massa, conforme prescreve a norma brasileira, também pode ter influenciado a queda na demanda de alimentos substitutos do leite materno nos anos de 1988, 1992 e 2002. Por outro lado, o período de relativa recuperação no patamar de vendas de alimentos substitutos do leite materno corresponde ao início do processo de estabilização da economia brasileira, após a implementação do Plano Real, que gerou significativa melhora da distribuição de renda no país $(26,27)$.

À luz dos resultados apresentados, uma questão central deveria ser enunciada: caso a totalidade dos requisitos de obediência e restrições à indústria estipuladas na Norma Brasileira de Comercialização de Alimentos para Lactentes e Crianças de Primeira Infância, Bicos, Chupetas e Mamadeiras fosse atendida, qual seria a magnitude do incremento nos indicadores de amamentação no Brasil, face à diversidade socioeconômica, educacional e cultural observada no contexto brasileiro, considerando-se a inadequação de atitudes, crenças e comportamentos dos agentes envolvidos? Em termos de comunicação social, é nítida a necessidade de um esforço social organizado em prol de mudanças consistentes ao longo do tempo.

A literatura sobre causas de desmame precoce aponta para a influência de múltiplas variáveis na decisão materna de amamentar. Estudos internacionais sobre fatores relacionados ao desmame precoce demonstram que variáveis como decisão de amamentar antes do parto, maior nível de informação sobre aleitamento materno durante a gestação, maior grau de educação formal e não-introdução de mamadeiras durante os primeiros dias de vida foram positivamente relacionadas com a duração da amamentação. Contrariamente, a crença materna de que o bebê prefere fórmulas infantis, a falta de confiança da mãe no sucesso do prosseguimento da amamentação e os fatores 
associados ao trabalho materno influenciaram significativamente o abandono precoce do aleitamento materno $(28,29)$.

As falhas críticas de regulação e as imperfeições na determinação do papel do governo contidas nas versões preliminares da norma brasileira podem explicar, pelo menos em parte, a falta de conhecimento sobre a norma brasileira detectada entre mães, médicos, profissionais de saúde e nutricionistas, agentes que deveriam atuar como filtros de ações comerciais oportunistas da indústria. $\mathrm{O}$ papel de empresas fabricantes de fórmulas infantis deveria se ater à comercialização de alimentos adequados à alimentação de bebês com necessidades especiais, ou seja, cujas mães estão impossibilitadas de praticar o aleitamento materno por ausência de leite, presença de doenças transmissíveis ao bebê ou outras situações atípicas. No entanto, esse papel vinha sendo distorcido, na medida em que as empresas buscavam agregar qualquer potencial consumidor à sua demanda, mesmo aqueles sem indicação de necessidades especiais.

A revisão de 2002 (16) incorporou parâmetros de monitoramento e sanções aplicáveis ao descumprimento da Norma Brasileira de Comercialização de Alimentos para Lactentes e Crianças de Primeira Infância, Bicos, Chupetas e Mamadeiras e designou a Agência Nacional de Vigilância Sanitária (ANVISA) como órgão oficial de fiscalização sistemática. Essas alterações podem apresentar resultados mais expressivos no combate à ocorrência de transgressões na promoção da comercialização de substitutos do leite materno e gerar impacto mais significativo em termos de duração da amamentação e adesão ao aleitamento materno exclusivo nos primeiros 6 meses de vida, tendo em vista o papel favorável da ANVISA na promoção da prática da amamentação no país.
A promoção do aleitamento materno no país deveria enfatizar a transcendência das barreiras culturais, educacionais e econômicas identificadas nos agentes envolvidos. A solução ideal no que tange à comercialização de alimentos substitutos do leite materno reside na minimização da assimetria informacional, possibilitando a formulação de escolhas individuais baseadas no livre arbítrio. Quanto mais complexo for o processo de avaliação do efeito de um produto pelo consumidor, mais exposto ele estará aos riscos da propaganda enganosa e da informação deturpada ou incompleta.

A solução legal de instituição de um marco regulatório, representado pela norma brasileira, teve resultados positivos; entretanto, constituiu apenas um paliativo à situação de baixo nível educacional da população, que pode gerar distorções ainda mais graves, como, por exemplo, o uso de produtos inapropriados ao consumo de lactentes, como demonstrado no presente estudo (a maioria das mães declarou introduzir alimentos inadequados ao bebê por aconselhamento de parentes e profissionais de saúde).

Outro aspecto frequentemente associado à suspensão do aleitamento materno refere-se à redução do tempo disponível da mãe pelo retorno ao trabalho. Em 2006, iniciou-se discussão acerca da possibilidade de modificação da lei trabalhista brasileira no sentido de aumentar o período da licença-maternidade a ser concedido às mães após o parto, buscando-se contemplar o período mínimo recomendado ao aleitamento materno exclusivo (6 meses). A ampliação da licença-maternidade para 180 dias, em caráter facultativo ao empregador face à oferta de incentivo fiscal, foi aprovada pela Comissão de Trabalho, de Administração e Serviço Público da Câmara dos
Deputados no mês de março de 2008 $(30,31)$. Divergências quanto à influência de tal medida sobre o nível de emprego entre mulheres têm gerado amplo debate sobre os benefícios esperados e potenciais custos associados à mudança na legislação. Entretanto, mesmo uma modificação adicional no texto legal poderia não reverter benefício algum, face ao descumprimento, pelos locais de trabalho, dos quesitos já estabelecidos, como observado nos resultados da pesquisa apresentada (por exemplo, falta de amparo à mãe no local de trabalho durante a fase de amamentação do bebê).

Ressalta-se que a análise descritiva de dados secundários, como a realizada no presente artigo, apresenta limitações quanto à estrita determinação de causalidade entre as variáveis, assim como quanto à robustez de alguns dados. Entretanto, a possibilidade de contribuir para uma melhor compreensão das causas de desmame precoce no Brasil constituiu o principal incentivo para a publicação destes resultados.

Em suma, pode-se afirmar que a ação coordenada entre agentes públicos, agentes privados e organizações não-governamentais na direção da promoção do conhecimento, informação e desejo de amamentar é obviamente desejável. Entretanto, é inevitável a persistência de alguns pontos secundários de descontentamento, tendo em vista a necessidade de concessões para contemplar a ampla diversidade de interesses dos diferentes agentes envolvidos no processo. A significativa resistência de determinados agentes à consolidação de parcerias e ações coordenadas entre setor público e setor privado deveria ser suprimida na busca de uma convergência institucional em prol do interesse maior expresso no contexto da norma brasileira: a proteção da saúde do lactente.

\section{REFERÊNCIAS}

1. Venâncio SI. A evolução da prática do aleitamento materno no Brasil nas décadas de $70 \mathrm{e}$ 80 [dissertação]. São Paulo: Universidade de São Paulo; 1996.

2. Heinig MJ, Dewey KG. Health advantages of breast feeding for infants: a critical review. Nutr Res Rev. 1996;9:89-110.

3. Victora CG, Smith PG, Vaughan JP, Nobre LC, Lombardi C, Teixeira AM, et al. Evidence for protection by breast-feeding against infant deaths from infectious diseases in Brazil. Lancet. 1987;2(8554):319-22.
4. Sheard NF, Walker WA. The role of breast milk in the development of the gastrointestinal tract. Nutr Rev. 1988;46(1):1-8.

5. Lawrence PB. Breast milk. Best source of nutrition for term and preterm infants. Pediatr Clin N Am. 1994;41(5):925-41.

6. Mitchell MK. Nutrition during infancy. Em: Mitchell MK. Nutrition across the life span. Filadélfia: Saunders; 1997.

7. Digirolamo AM, Grummer-Strawn LM, Fein S. Maternity care practices: implications for breastfeeding. Birth. 2001;28(2):94-100.
8. Kummer SC, Giugliani ERJ, Susin LO, Folletto JL, Lermen NR, Wu VYJ, et al. Evolução do padrão de aleitamento materno. Rev Saude Publica. 2000;34(2):143-8.

9. Venâncio SI, Monteiro CA. A evolução da prática da amamentação nas décadas de 70 e 80. Rev Bras Epidemiol. 1998;1(1):40-9.

10. Brasil, Ministério da Saúde, Conselho Nacional de Saúde. Resolução 5, de 20 de dezembro de 1988. Normas para comercialização de alimentos para lactentes. Brasília: Ministério da Saúde; 1989. 
11. World Health Organization, United Nations Children's Fund. International Code of Marketing of Breast-milk Substitutes. Genebra: WHO/UNICEF; 1981. Disponível em: http:/ / www.who.int/nutrition/publications / infantfeeding/code_english.pdf. Acessado em 08 de janeiro de 2009.

12. Monteiro R. Norma brasileira de comercialização de alimentos para lactentes e crianças de primeira infância: histórico, limitações e perspectivas. Rev Panam Salud Publica. 2006; 19(5):354-62.

13. Araújo MFM, Rea MF, Pinheiro KA, Schmitz BAS. Avanços na norma brasileira de comercialização de alimentos para idade infantil. Rev Saude Publica. 2006;40(3):513-20.

14. Rea MF, Toma TS. Proteção do leite materno e ética. Rev Saude Publica. 2000;34(4):388-95.

15. Cyrillo DC. Reconstruindo instituições: o caso da Norma Brasileira de Comercialização de Alimentos para Lactentes [tese de livredocência]. São Paulo: Universidade de São Paulo; 2001.

16. Brasil, Ministério da Saúde. Portaria 2.051, de 8 de novembro de 2001. Norma brasileira de comercialização de alimentos para lactentes e crianças de primeira infância, bicos, chupetas e mamadeiras. Brasília: Ministério da Saúde; 2001. Disponível em: http:/ / www2.rio.rj.gov. $\mathrm{br} /$ governo/vigilanciasanitaria/legislacao/ portfederal2051_01.pdf. Acessado em 20 de dezembro de 2008.

17. Aguayo VM, Ross JS, Kanon S, Ouedraogo AN. Monitoring compliance with the International Code of Marketing of Breastmilk Substitutes in West Africa: multisite cross sectional survey in Togo and Burkina Faso. BMJ. 2003;326(7381):127-32.
18. Taylor A. Violations of the International Code of Marketing of Breast-milk Substitutes: prevalence in four countries. BMJ. 1998;316(7138): 1117-22.

19. Araújo MFM. Situação e perspectivas do aleitamento materno no Brasil. Em: Carvalho MR, Tamez RN. Amamentação: bases científicas para a prática profissional. Rio de Janeiro: Guanabara Koogan; 2002.

20. Machado FMS. Estratégias de concorrência da indústria alimentícia e seus desdobramentos na dimensão nutricional [tese]. São Paulo: Universidade de São Paulo; 2003.

21. Instituto Brasileiro de Geografia e Estatística. Estatísticas do Registro Civil: nascidos vivos registrados no ano, 1986-2002. Rio de Janeiro: IBGE; 2003. Disponível em: http://www. sidra.ibge.gov.br/bda/pesquisas / rc/ default.asp? $0=8 \& \mathrm{i}=\mathrm{P}$. Acessado em 08 de janeiro de 2009.

22. Henderson L, Kitzinger J, Green J. Representing infant feeding: content analysis of British media portrayals of bottle feeding and breast feeding. BMJ. 2000;321(7270):1196-8.

23. World Health Organization, United Nations Children's Fund. Protecting, promoting and supporting breastfeeding: the special role of maternity services. Genebra: WHO/UNICEF; 1989.

24. Toma TS. Iniciativa Hospital Amigo da Criança: diagnóstico das práticas de alimentação infantil em maternidades públicas e privadas do município de São Paulo [dissertação]. São Paulo: Universidade de São Paulo; 1998.

25. Venancio SI, Escudera MML, Kitoko P, Rea MF, Monteiro CA. Freqüência e determinantes do aleitamento materno em municípios do Estado de São Paulo. Rev Saude Publica. 2002; 36(3):313-8.
26. Farina EMMQ, Nunes R. A evolução do sistema agroalimentar no Brasil e a redução de preços para o consumidor: os efeitos da atuação dos grandes compradores. Rio de Janeiro: Instituto de Pesquisa Econômica Aplicada; 2003. (Texto para Discussão 970.)

27. Cyrillo DC, Saes MSM, Braga MB. Tendências do consumo de alimentos e o Plano Real: uma avaliação para a Grande São Paulo. Planejamento e Políticas Públicas. 1997;16:163-95.

28. Ertem IO, Votto N, Leventhal JM. The timing and predictors of the early termination of breastfeeding. Pediatrics. 2001;107(3):543-8.

29. González MDE, Cebrián DM, Santana RM, Villanueva EG, Santana PS. Factores relacionados con el abandono de la lactancia materna. An Esp Pediatr. 2002;56(2):144-50.

30. Brasil, Senado Federal. Projeto de Lei do Senado $281 / 05$, de 10 de agosto de 2005. Brasília: Senado Federal; 2005.

31. Brasil, Câmara dos Deputados. Projeto de Lei 2.513/07. Parecer da Comissão de Trabalho, de Administração e Serviço Público. Em: Diário da Câmara dos Deputados de 27 de março de 2008. Brasília: Câmara dos Deputados; 2008. Pp. 11466-7. Disponível em: http:/ / imagem.camara.gov.br/pdf.asp?Destino= http $\% 3 \mathrm{~A} \% 2 \mathrm{~F} \% 2$ FImagem \%2Ecamara\%2Egov $\% 2$ Ebr $\% 2$ FImagem $\% 2$ Fd $\% 2 F p d f \% 2 F D C D 27$ MAR2008\%2Epdf\%23page\%3D1. Acessado em 20 de dezembro de 2008.

Manuscrito recebido em 23 de novembro de 2007. Aceito em versão revisada em 14 de maio de 2008.
ABSTRACT

\section{Two decades of the Brazilian Standard for Marketing of Baby Food: are there reasons to celebrate?}

Key words
Objective. To assess the impact that the Brazilian Standard for Marketing of Baby Food (Norma Brasileira de Comercialização de Alimentos para Lactentes) have had on breastfeeding rates and regulating the marketing of breast-milk substitutes.

Methods. Data were retrieved from a national survey conducted in 2000 that administered structured questionnaires to nine different groups. A total of 2848 surveys were completed. Cluster sampling was employed to randomly select a sample from 159 towns located in the 26 Brazilian states and the Federal District.

Results. The survey showed that participants possess satisfactory knowledge regarding the importance of breastfeeding and its ideal duration period. During the past two decades, the median duration of breastfeeding has increased, but it is still below desired levels. The mother's return to work, maternal health issues, perception of insufficient breast milk, and information provided by health professionals were among reasons given for early termination of breastfeeding. Knowledge of the Brazilian standard was very limited, even among health professionals.

Conclusions. Breastfeeding promotion in Brazil should focus on overcoming the cultural, educational, and economic barriers identified from among the various groups assessed. Interagency cooperation should include public, private, and thirdparties, and focus on disseminating breastfeeding information and promoting the desirability of breastfeeding. Barriers to cooperation should be tackled in order to ensure that the main goal of the Brazilian standard-protection of infant health-can be achieved.

Breast feeding; infant formula; legislation, medical; health policy; health promotion, Brazil. 